\title{
Assessment of Anti-oxidant Activity of Aerial Parts of Mangrove Plant, Derris trifoliata (Leguminosae)
}

\author{
Arif Hossin, Beton Chakma and Ali Imam Raju
}

\section{ABSTRACT}

The current study was conducted to verify the traditional medicinal use and to carry out the in-vitro antioxidant activity of various solvent extracts of Derris trifoliata (aerial part). The percentage yield of ethanol, ethyl acetate and n-hexane extracts were found $2.5 \% \mathrm{w} / \mathrm{w}$. Freshly prepared extracts were subjected to preliminary phytochemical screening. All extracts revealed the presence of several important phytochemicals which might be responsible for its medicinal properties. In vitro Electron transfer (ET) reaction-based assays of ethanol, ethyl acetate and n-hexane extracts have been investigated using various model systems viz., DPPH, total phenolic, tannin and flavonoid content, ferric ion reducing antioxidant power (FRAP) and reducing power assay. Hydrogen atom transfer (HAT) reaction-based assays have been conducted using Nitric Oxide (NO) scavenging and hydrogen peroxide scavenging activity assay methods. Ethanol extract was found to possess highest DPPH $\left(\right.$ IC $_{50}=16.824 \mu \mathrm{g} / \mathrm{ml}$ ), total phenolic content (44.51 GAE/g of dried plant extract), reducing power assay $(0.387 \pm 0.0006)$, FRAF assay $\left(\mathrm{IC}_{50}=133.51 \mu \mathrm{g} / \mathrm{ml}\right)$, hydrogen peroxide scavenging $\left(\mathrm{IC}_{50}=144.888 \mu \mathrm{g} / \mathrm{ml}\right)$ and nitric oxide scavenging activities $\left(\mathrm{IC}_{50}=152.655 \mu \mathrm{g} / \mathrm{ml}\right)$. Whereas ethyl acetate extract was found to possess the highest total tannin content $(42.56 \mathrm{GAE} / \mathrm{g}$ of dried plant extract) and total flavonoid content $(78.08 \mathrm{QE} / \mathrm{g}$ of dried plant extract). In vitro antioxidant study was also performed in terms of chelation power on ferrous ions. The highest chelation power was found for ethyl acetate extract $\left(\mathrm{IC}_{50}=62.489 \mu \mathrm{g} / \mathrm{ml}\right)$. The above study suggests that Derris trifoliata may be a vital source of nutraceuticals.

Keywords: Derris trifoliata, flavonoid content, scavenging and assay quantitative anti-oxidant activity, total phenol tannin.

\section{INTRODUCTION}

Derris trifoliata Lour, is an evergreen mangrove shrub occurring in the tropical regions of Asia and East Africa, belongs to the Leguminosae, which is locally known as pan lota, kali lota and goali lata [1]. It is a large climber; branched glabrous plant, usually grows in the muddy seacoast, creeks and also found in Sundarbans of Bangladesh. The aerial parts of the plant are characterized by $7.5-15 \mathrm{~cm}$ ovate-oblong, subacute flowers, $2.5 \mathrm{~mm}$ calyx, $2.5-3.5 \mathrm{~cm}$ variable pods, reinform and compressed seeds, $12.5-20 \mathrm{~cm}$ leaves having 3$7 \mathrm{~cm}$ ovate or ovate oblong leaflets and a dark-gray bark covered with scattered lenticels. Being known as a poisonous plant, it is used locally for catching fish, and nowadays also used extensively for the control of insect pests [2]. However, different parts of the plant are used in traditional medicine for treatment of wounds, calculus, rheumatism and dysmenorrhea and asthma [3]. This plant's extracts and metabolites have been found to possess significant antiinflammatory, antimicrobial, larvicidal, pesticidal, nitric oxide inhibitory, cytotoxic, anti-fungal, and cancer chemopreventive activities [4]-[7]. It has been found from previous phytochemical investigations on Derris trifoliata that the most characteristic compounds of this plant are flavonoids, including rotenoids [8].

The prime interest of the current study was screening the sources of related bioactive compounds responsible for antioxidant property from its aerial part. These investigations might lead to development of new prophylactic and therapeutic $\operatorname{drug}(\mathrm{s})$ that may contribute benefits in national and international health care sector as nutraceuticals.

\section{MATERIALS AND METHODS}

\section{A. Collection and Preparation of Crude Extract}

Aerial parts of Derris trifoliata Lour were collected from Sundarbans, mangrove forests Bangladesh. The plants were dried by shade drying and grinded into powder (approximately $500 \mathrm{~g}$ ). Hot extraction by Soxhlet apparatus was performed with solvent ethanol, ethyl acetate and nhexane to obtain $46 \mathrm{~g}, 15 \mathrm{~g}$ and $9 \mathrm{~g}$ crude extracts respectively. The extracts were stored in an airtight container and kept in a cool, dark and dry place until analysis commenced.

\section{B. Phytochemical Screening}

The extracts were subjected to various phytochemical tests to identify the presence of active compounds. Standard 
investigation for reducing sugar (Fehling's and Benedict's tests), alkaloids (Mayer's and Dragendroff's tests), glycosides, proteins-xanthoprotein, terpenoids (Salkowski test), tannin (Ferric chloride and Potassium dichromate test), flavonoids (Saponins and carbohydrates/gums tests), steroids (Libermann-Burchard and sulphuric acid tests) were performed according to established protocols [9].

\section{DPPH Free Radical Scavenging Assay}

The antioxidant potential of different extracts was determined on the basis of their scavenging activity of the stable 2, 2-diphenyl-1-picryl hydrazyl (DPPH) free radical [10]. The aliquots of the different concentrations $(1-256 \mu \mathrm{g}$ $/ \mathrm{ml}$ ) of the extract were added to $3 \mathrm{ml}$ of a $0.004 \% \mathrm{w} / \mathrm{v}$ solution of DPPH. Absorbance at $517 \mathrm{~nm}$ was taken after 30 min, and $\mathrm{IC}_{50}$ (Inhibitory concentration 50\%) was determined. $\mathrm{IC}_{50}$ value denotes the concentration of sample required to scavenge $50 \%$ of the DPPH free radicals [11]. The equation (1) used for $\%$ inhibition ratio:

$$
\text { Percent Inhibition or I }(\%)=\frac{A_{0}-\mathrm{A}}{A_{0}} \times 100
$$

where $A_{o}$ is the absorbance of the control solution (containing all reagents except plant extracts); $\mathrm{A}$ is the absorbance in the presence of the sample of plant extracts.

\section{Total Phenolic content Assay}

The total phenolic content of Derris trifoliata was determined by the modified Folin-Ciocalteu method [12]. The standard curve was prepared using $0,0.1 ; 0.2 ; 0.3 ; 0.4$ and $0.5 \mathrm{mg} / \mathrm{ml}$ solutions of Gallic Acid in methanol: water (50:50, $\mathrm{v} / \mathrm{v})$. Then total phenolic content (TPC) in plant ethanol extract in gallic acid equivalent (GAE) was calculated by using the following equation (2):

$\mathrm{TPC}(\mathrm{mg} \mathrm{GAE} / \mathrm{g})=\frac{\mathrm{GAE}}{\text { Sample concentration }(\mathrm{g} / \mathrm{ml})}$

\section{E. Total Tannin Content Assay}

The total tannin content of Derris trifoliata was determined by the method followed by Amorim et al. [13]. The standard curve was prepared using $0,0.1 ; 0.2 ; 0.3 ; 0.4$ and $0.5 \mathrm{mg} / \mathrm{ml}$ solutions of Gallic Acid in water. All determinations were performed in triplicate.

\section{F. Total Flavonoid Content Assay}

The aluminum chloride colorimetric method was modified from a procedure [14]. The standard curve was prepared using $0,0.1 ; 0.2 ; 0.3 ; 0.4$ and $0.5 \mathrm{mg} / \mathrm{ml}$ solutions of Quercetin in methanol.

\section{G. Reducing Power Assay}

Reducing power of ethanol, ethyl acetate and n-hexane extracts were determined by slight modification of Oyaizu et al. [15]. Substances which have reduction potentials $\left(\mathrm{Fe}^{3+}\right)$, reacts with potassium ferrocyanide $\left(\mathrm{Fe}^{2+}\right)$ which then reacts with ferric chloride to form ferric ferrous complex that has an absorption maximum at $700 \mathrm{~nm}$. In this assay, the change of yellow color of the test solution to green and blue depending on the reducing power of test specimen was observed [16].

$$
\begin{gathered}
K_{3}\left[\mathrm{Fe}^{3} \mathrm{CN}_{6}\right]+\mathrm{e} \text { (antioxidant) }=K_{4}\left[\mathrm{Fe}^{2}(\mathrm{CN})_{6}\right] \\
\text { Potassium ferricyanide Potassium ferrocyanide } \\
\mathrm{FeCl}_{3}+K_{4}\left[\mathrm{Fe}^{2}(\mathrm{CN})_{6}\right]=K_{\mathrm{Fe}^{3}\left[\mathrm{Fe}^{2}(\mathrm{CN})_{6}\right]}
\end{gathered}
$$

Ferric chloride Potassium ferrocyanide Prussian Blue

Increased absorbance of the reaction mixture was considered indication for increased reducing power [17].

\section{H. Hydrogen Peroxide Scavenging Activity}

The hydrogen peroxide scavenging assay was carried out following the procedure used by Ruch et al. [18]. The abilities to scavenge the hydrogen peroxide were calculated using the following equation (3).

$$
H_{2} \mathrm{O}_{2} \text { scavenging activity }=\frac{A_{0}-\mathrm{A}}{A_{0}} \times 100
$$

where $A_{o}$ is the absorbance of the control solution (containing all reagents except plant extracts); $\mathrm{A}$ is the absorbance in the presence of the sample of plant extracts.

\section{Nitric Oxide (NO) Scavenging Assay}

The nitric oxide scavenging activity was conducted based on the Greiss Assay method [19]. Sodium nitroprusside (5 $\mathrm{mmol}$ ) in phosphate buffered saline was mixed with different concentrations of the extract $(5-100 \mathrm{mg} / \mathrm{ml})$ dissolved in suitable solvent system and incubated at $25{ }^{\circ} \mathrm{C}$ for 30 minutes. After 30 minutes of incubation $1.5 \mathrm{ml}$ solution was taken and diluted with1.5 $\mathrm{ml}$ of Griess reagent $(1 \%$ sulphanilamide, $2 \%$ phosphoric acid and $0.1 \%$ naphthylethylenediamine dihydrochloride). The absorbance of the chromophore formed during diazotization of the nitrite with sulphanilamide and subsequent coupling with naphthylethylenediamine dihydrochloride was measured at $546 \mathrm{~nm}$ with a double beam Analykjena UV/Visible Spectrophotometer [20]. The nitric oxide (NO) radical scavenging activity was expressed as the inhibition percentage (I\%) and calculated as per the equation (4):

$$
\text { Percent Inhibition }(\mathrm{I} \%)=\frac{A_{0}-\mathrm{A}}{A_{0}} \times 100
$$

where $\mathrm{A}_{\mathrm{o}}$ is the absorbance of the control solution (containing all reagents except plant extracts); $\mathrm{A}$ is the absorbance in the presence of the sample of plant extracts.

\section{J. FRAP (Ferric Reducing Antioxidant Power) Assay}

The Ferric Reducing Antioxidant power of ethanol extract of plants was determined by the method used by Benzie and Strain [21]. Plant extracts $(0.15 \mathrm{ml})$ and standard solutions $(0.15 \mathrm{ml})$ of different concentrations $(500,200,100,50$, and $25 \mu \mathrm{g} / \mathrm{ml}$ ) were allowed to react with $2.85 \mathrm{ml}$ of FRAP solution for $30 \mathrm{~min}$ in the dark condition. After 30 minutes, absorbance of the colored product (Ferrous tripyridyltriazine complex) was taken against control at $593 \mathrm{~nm}$ with Shimadzu UV/ visible spectrophotometer (Model 1800, Japan). Control was prepared in similar manner excluding sample/standard. 


\section{K. Ferrous Ion $(\mathrm{Fe}++)$ Chelating Ability Assay}

The ferrous chelating abilities of the fractions were monitored by measuring the formation of the ferrous ion ferrozine complex following a standard spectrophotometric method with minor changes [22]. $5 \mathrm{ml}$ of sample of different concentration $(5,10,20,40,60,80$ and $100 \mu \mathrm{g} / \mathrm{ml})$ in different test tubes were added to $0.1 \mathrm{ml}$ solution of $2 \mathrm{mM}$ $\mathrm{FeCl}_{2}$ and $3.7 \mathrm{ml}$ methanol. Then, the reaction was initiated by the addition of $0.2 \mathrm{~m} 1$ of $5 \mathrm{mM}$ Ferrozine and mixture was shaken vigorously and left standing at room temperature for $10 \mathrm{~min}$. After the mixture had reached equilibrium, the absorbance of the solution was then measured spectrophotometrically at $562 \mathrm{~nm}$ in spectrophotometer. The percentage of inhibition of ferrozine- $\mathrm{Fe}^{2+}$ complex formation was given in the below equation (5):

$$
\text { Ferrous ions chelating ability }(\%)=\frac{A_{0}-\mathrm{A}}{A_{0}} \times 100
$$

where $A_{o}$ is the absorbance of the control solution (containing all reagents except plant extracts); $\mathrm{A}$ is the absorbance in the presence of the sample of plant extracts. The control contains $\mathrm{FeCl}_{2}$ and ferrozine, complex formation molecules. The $\mathrm{IC}_{50}$ value was compared with EDTA (Ethylenediaminetetraacetic acid).

\section{RESUlts AND DiscussiON}

\section{A. Phytochemical Screening}

Ethanol extract of Derris trifoliata and its partitioned parts were subjected for chemical group tests and observation of different group tests are given in the Table I.

TABLE I: RESUlT OF PHYTOCHEMICAL TESTS

\begin{tabular}{cccc}
\hline \hline Test for & $\begin{array}{c}\text { Ethanol } \\
\text { extract }\end{array}$ & $\begin{array}{c}\text { N-hexane } \\
\text { extract }\end{array}$ & $\begin{array}{c}\text { Ethyl acetate } \\
\text { extract }\end{array}$ \\
\hline Reducing Sugars & + & - & + \\
Saponins & + & - & + \\
Alkaloids & + & + & + \\
Flavonoids & + & + & + \\
Tannins & + & - & + \\
Gums & + & + & - \\
Steroid & + & + & + \\
\hline \hline
\end{tabular}

The tests carried out on Derris trifoliata extract revealed the presence of several important phytochemicals which might be responsible for its medicinal properties.

\section{B. DPPH Free Radical Scavenging Assay}

In the quantitative assay, Derris trifoliata displayed free radical scavenging activity in the DPPH assay which is comparable to that of L-ascorbic acid, a well-known standard antioxidant (Fig. 1). The activity was in the following order: Ethanol extract $>$ Ethyl acetate extract $>$ n-Hexane extract. However, this assay may be used to guide the fractionation and isolation of potential antioxidant compounds from this mangrove plant.

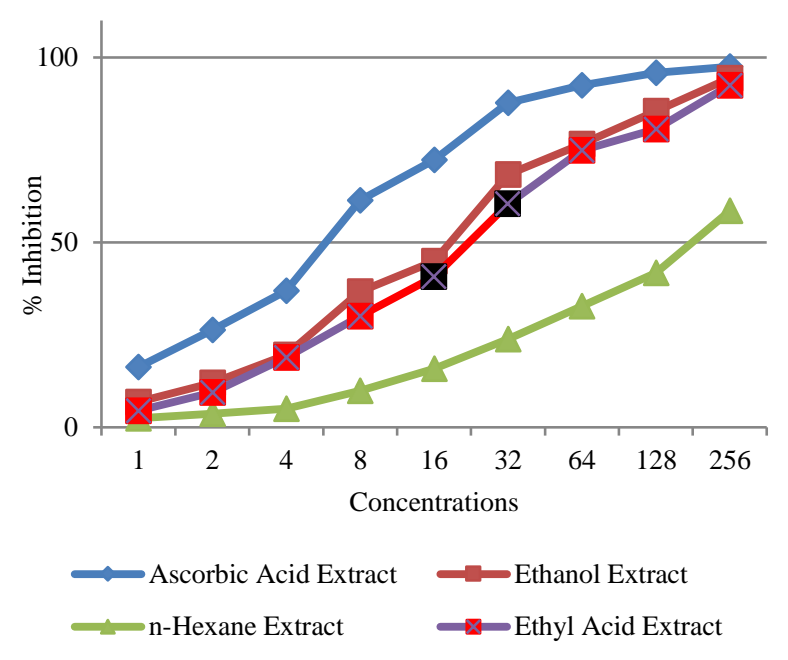

Fig. 1. Comparison of $\%$ inhibition of ascorbic acid (standard) and various samples of Derris trifoliata.

The ethanol and ethyl acetate extracts of Derris trifoliata exhibited a significant dose dependent inhibition of DPPH activity, with a $50 \%$ inhibition $\left(\mathrm{IC}_{50}\right)$ at a concentration of $16.824 \mu \mathrm{g} / \mathrm{ml}$ and $21.3487 \mu \mathrm{g} / \mathrm{ml}$ respectively (Fig. 2). The $\mathrm{IC}_{50}$ values of the extract were found to be comparable to reference standard ascorbic acid $\left(\mathrm{IC}_{50}: 5.693 \mu \mathrm{g} / \mathrm{ml}\right)$. The reducing ability of a compound generally depends on the presence of reductants [23], which have been exhibited antioxidative potential by breaking the free radical chain, donating a hydrogen atom [24].

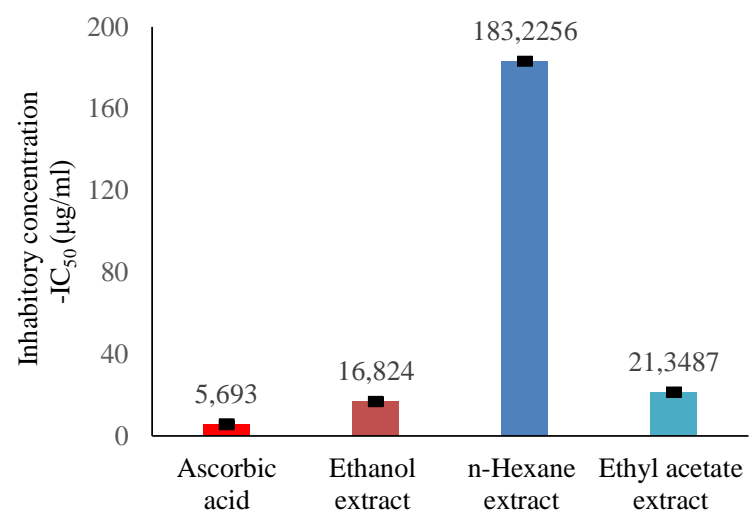

Fig. 2. $\mathrm{IC}_{50}$ values of standard (ascorbic acid) and different samples of Derris trifoliata. The results are represented as mean SEM (standard error of the mean).

The effect of antioxidants on DPPH radical scavenging is thought to be due to their hydrogen donating ability. DPPH is a stable free radical and accepts an electron or hydrogen radical to become a stable diamagnetic molecule. The model of scavenging the stable DPPH radical is a widely used method to evaluate antioxidant activities in a relatively short time compare to other methods [25]. The reduction capability on the DPPH radical is determined by the decrease in its absorbance at $517 \mathrm{~nm}$ induced by antioxidants. The maximum absorption of a stable DPPH radical in ethanol is at $517 \mathrm{~nm}$. The decrease in absorbance of DPPH radical caused by antioxidants is due to the reaction between antioxidant molecules and radical, which results in the scavenging of the radical by hydrogen donation. This is visualized as a discoloration from purple to yellow. Hence, 
DPPH is usually used as a substrate to evaluate antioxidant activity [26]-[28]. The $\mathrm{IC}_{50}$ of the plant extracts are compared to that of a standard, ascorbic acid.

\section{Total Phenolic Content Assay}

Phenolic compounds and polyphenols are the most abundant structures in plants. Antioxidant compounds are usually in the phenolic form. The antioxidant properties of phenolic compounds originate from their properties of proton loss, chelate formation, and dismutation of radicals. In fact, in some studies, theoretical methods have been proposed to estimate the antioxidant activities of phenolic substances. Their structure-activity relationships are examined for this purpose. Phenols are compounds that have the ability to destroy radicals because they contain hydroxyl groups. These important plant components give up hydrogen atoms from their hydroxyl groups to radicals and form stable phenoxyl radicals; hence, they play an important role in antioxidant activity. Therefore, determination of the quantity of phenolic compounds is very important in order to determine the antioxidant capacity of plant extracts [29]-[31]. The amount of total phenolic was determined with the Folin-Ciocalteu reagent. Gallic acid was used as standard and the total phenolicic content was expressed in terms of milligram of gallic acid equivalent (GAE) per gram of dry extract using the standard curve equation (Fig. 3):

$$
f(x)=y=8.8146 x+0.1747 ; R^{2}=0.9932
$$

where $\mathrm{y}$ is absorbance at $765 \mathrm{~nm}$ and $\mathrm{x}$ is total phenolic content in the different samples of Derris trifoliata.

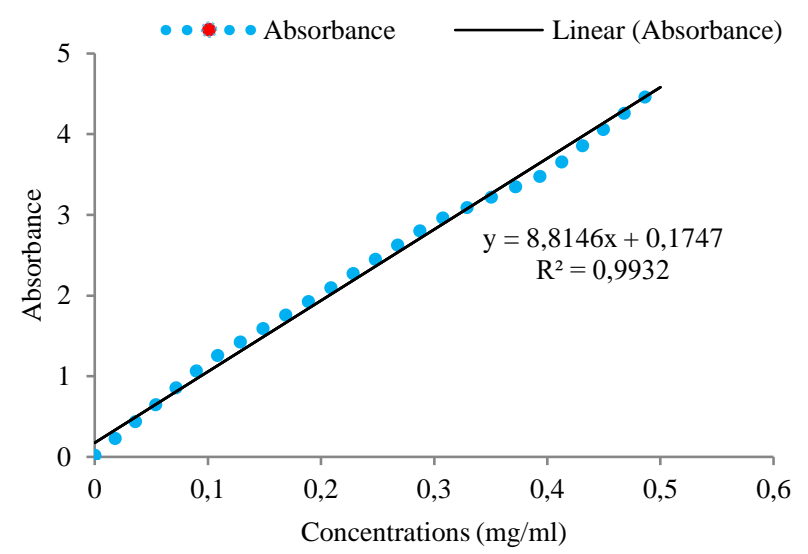

Fig. 3. The calibration curve of standard Gallic acid.

Total phenolic content value is expressed in terms of milligram of gallic acid equivalent (GAE) per gram of dry extract, which is a common reference compound. Total phenolic content was in following order: Ethanol extract> Ethyl acetate extract> n-Hexane extract (Fig. 4).

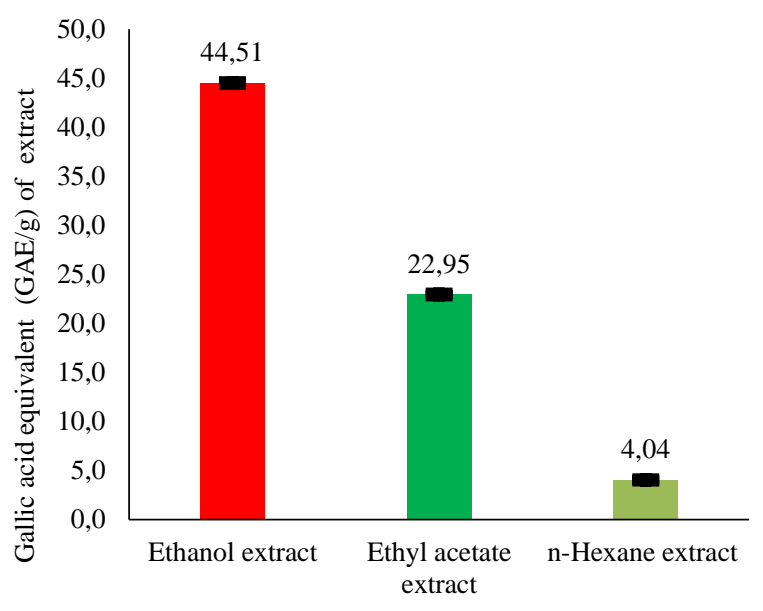

Fig. 4. Total phenolic content of different samples of Derris trifoliata. The results are represented as mean SEM (standard error of the mean).

\section{Total Tannin Content Assay}

The tannins are widely distributed in almost all plant foods, species [32]. Although phenolic compounds have been related to antioxidant activity, some studies have emphasized specific classes, such as the flavonoids and tannins [33]. Tannins have been reported to possess anticarcinogenic and antimutagenic potentials as well as antimicrobial properties. The amount of total tannin was determined with the FolinCiocalteu reagent. Gallic acid was used as standard and the total tannin content was expressed in terms of milligram of gallic acid equivalent (GAE) per gram of dry extract using the standard curve (Fig. 5) equation:

$$
y=1.0917 x+0.0172 ; R^{2}=0.9745
$$

where $\mathrm{y}$ is absorbance at $725 \mathrm{~nm}$ and $\mathrm{x}$ is total tannin content in the different samples of Derris trifoliata.

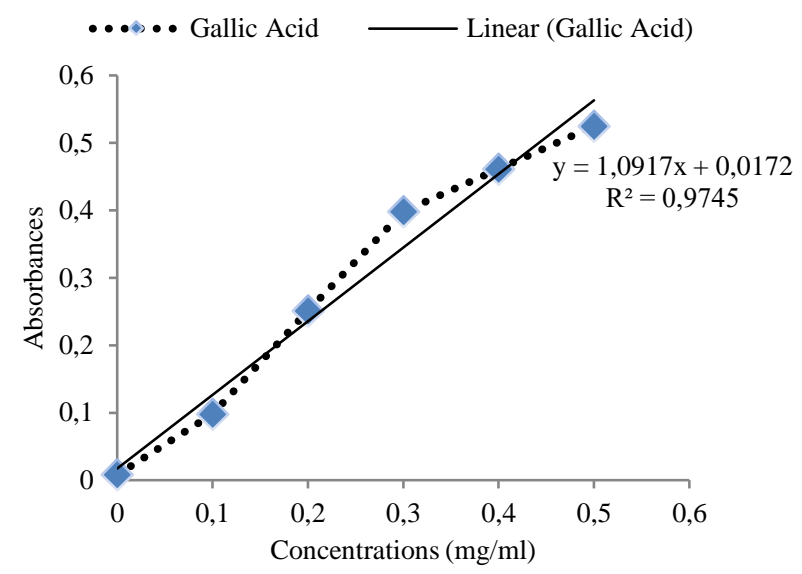

Fig. 5. The calibration curve of standard Gallic acid.

Based on the measured absorbance of extract, Gallic Acid Equivalent (GAE) was read. Total tannin content value is expressed in terms of milligram of gallic acid equivalent (GAE) per gram of dry extract. Total tannin content was in the following order: Ethyl acetate extract $>$ Ethanol extract> n-Hexane extract (Fig. 6). Present study suggest that nhexane extract contains very little amount (18.75 mg GAE/g) of tannins. 


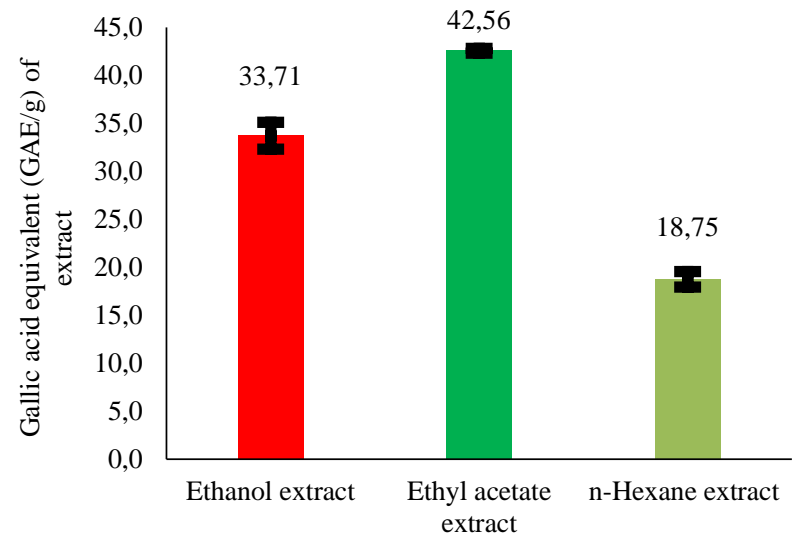

Fig. 6. Total tannin content of different samples of Derris trifoliata. The results are represented as mean SEM (standard error of the mean).

\section{E. Total Flavonoid content Assay}

Within the antioxidant compounds, flavonoids with a large distribution in nature, have been studied more comprehensively [34]-[36]. Flavonoids are known for their significant antioxidant properties and the flavonoid content of the investigated plant is of interest when evaluating its antioxidant properties [37]. The positions of the substituents also affect the physiological properties of different flavonoids. The flavonols having ortho or para hydroxyl group in the 2- phenyl ring is known to have strong antioxidant properties, while free hydroxyl at the 5, 7positions proved to have a pro-oxidant effect. A positive correlation between the content of flavonoids and the antioxidant capacity in plant extract has been found [38].

The amount of total flavonoid was determined by aluminum chloride colorimetric method. Quercetin was used as standard and the total flavonoid content was expressed as $\mathrm{mg} \mathrm{QE} / \mathrm{g}$ of dried plant material using the standard curve (Fig. 7) equation: $y=0.4649 x+0.0127, R^{2}=0.9881$, Where $\mathrm{y}$ is absorbance at $510 \mathrm{~nm}$ and $\mathrm{x}$ is total flavonoid content in the different samples of Derris trifoliata.

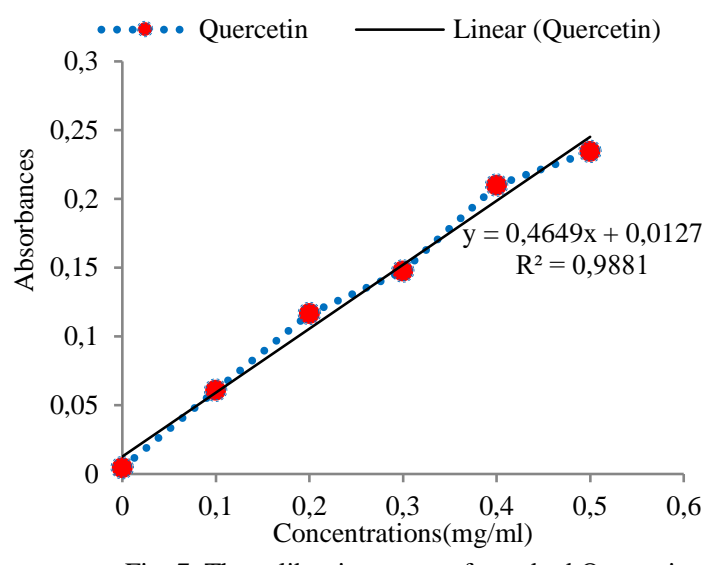

Fig. 7. The calibration curve of standard Quercetin.

The ethanol extract of Derris trifoliata was found to have a content of $50.84 \mathrm{mg}$ quercetin equivalents per gram of the dry weight extract. The ethyl acetate fraction of Derris trifoliata contains total flavonoids of $78.08 \mathrm{mg}$ quercetin equivalents per gram of the dry weight extract. Total flavonoid content was found in the following order: Ethyl acetate extract $>$ Ethanol extract $>$ n-Hexane extract (Fig. 8).

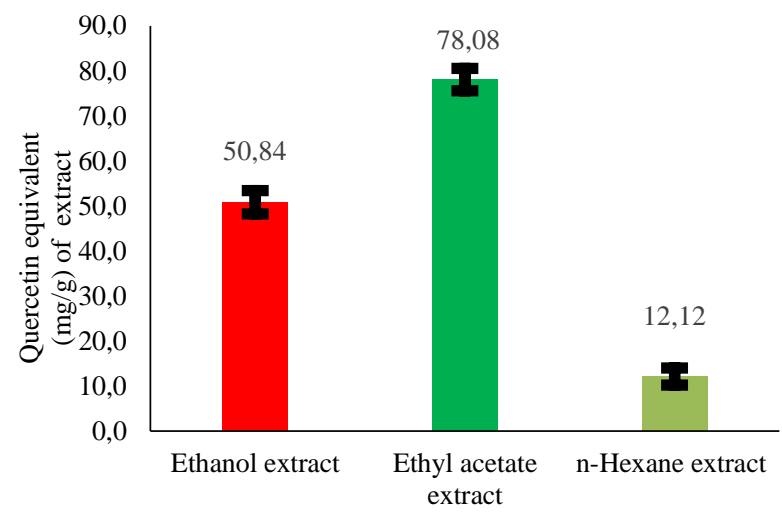

Fig. 8. Total flavonoid content of different samples of Derris trifoliata. The results are represented as mean SEM (standard error of the mean).

\section{F. Reducing Power Assay}

Although a reductant is not necessarily an antioxidant, an antioxidant is commonly a reductant [39]. The reducing power of a compound may therefore serve as a significant indicator of its potential antioxidant activity [40]. Ethanol extract showed highest reducing power in comparison to other samples of the extract (Fig. 9). Then Ethyl acetate extract showed second maximum activity and n-hexane part was fourth in position.

The reducing power of a compound is related to its electron transfer ability and may serve as a significant indicator of its potential antioxidant activity. In this assay, the yellow color of the test solution changes to green and blue depending on the reducing power of test specimen. Greater absorbance at $700 \mathrm{~nm}$ indicated greater reducing power. Figure 5 presents the reductive capabilities of the standard BHT (Butylated hydroxytoluene) and ethanol, ethyl acetate and n-hexane extracts of Derris trifoliata. In the concentration range investigated, all the extracts demonstrated reducing power that increased linearly with concentration. The highest average absorbance among the extracts was found to be $0.387 \pm 0.0006$ for ethanol extract. The reducing power of the extract might be due to their hydrogen-donating ability. Possibly, Derris trifoliata contains high amounts of reductive, which could react with radicals to stabilize and terminate radical chain reactions.

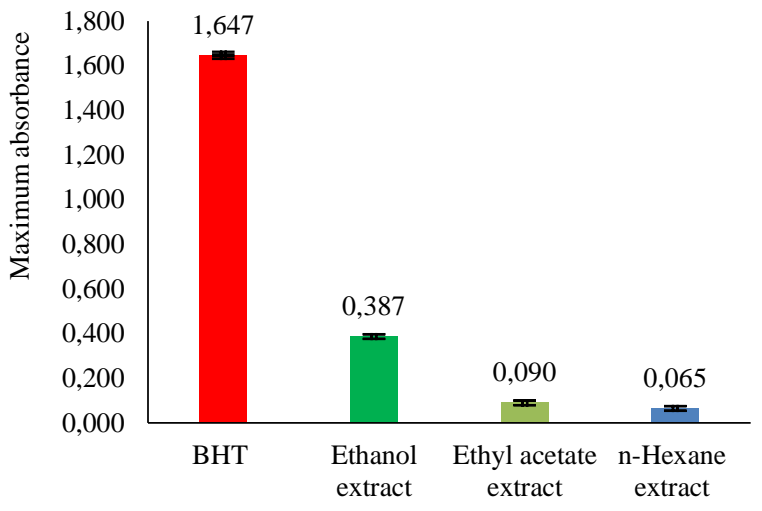

Fig. 9. Comparison of reducing power of BHT (standard) and various samples of Derris trifoliata. The results are represented as mean SEM (standard error of the mean).

\section{G. Hydrogen Peroxide Scavenging Activity}

Hydrogen peroxide is a weak oxidizing agent that 
inactivates a few enzymes directly, usually by oxidation of essential thiol (-SH) groups. It can cross cell membranes rapidly; once inside the cell, it can probably react with $\mathrm{Fe}^{2+}$ and possibly $\mathrm{Cu}^{2+}$ ions to form hydroxyl radicals and this may be the origin of many of its toxic effects [41]. Hydrogen peroxide itself is not very reactive; however, it can sometimes be toxic to cell, because it may give rise to hydroxyl radical in the cells. Hydrogen peroxide may enter into the human body through inhalation of vapor or mist and through eye or skin contact. $\mathrm{H}_{2} \mathrm{O}_{2}$ is rapidly decomposed into oxygen and water and this may produce hydroxyl radicals $(\mathrm{OH})$ that can initiate lipid per-oxidation and cause DNA damage in the body. The ability of plant extracts to scavenge hydrogen peroxide can be estimated by hydrogen peroxide scavenging assay.

The scavenging activity of Ascorbic acid, Ethanol extract, Ethyl acetate extract, n-Hexane extract is shown in Fig. 11. The extracts were capable of scavenging the hydrogen peroxide in a concentration dependent manner. $\mathrm{IC}_{50}$ for $\mathrm{H}_{2} \mathrm{O}_{2}$ scavenging activity were $144.888,236.95$ and $342.742 \mu \mathrm{g} / \mathrm{ml}$ for ethanol, ethyl acetate and n-hexane extracts respectively (Fig. 11). Ascorbic acid showed very strong activity $\left(\mathrm{IC}_{50}=\right.$ $53.613 \mu \mathrm{g} / \mathrm{ml}$ ). These results showed that Derris trifoliata had effective $\mathrm{H}_{2} \mathrm{O}_{2}$ scavenging activity and it was in the following order: Ascorbic acid> Ethanol extract> Ethyl acetate extract $>$ n-Hexane extract (Fig. 10).
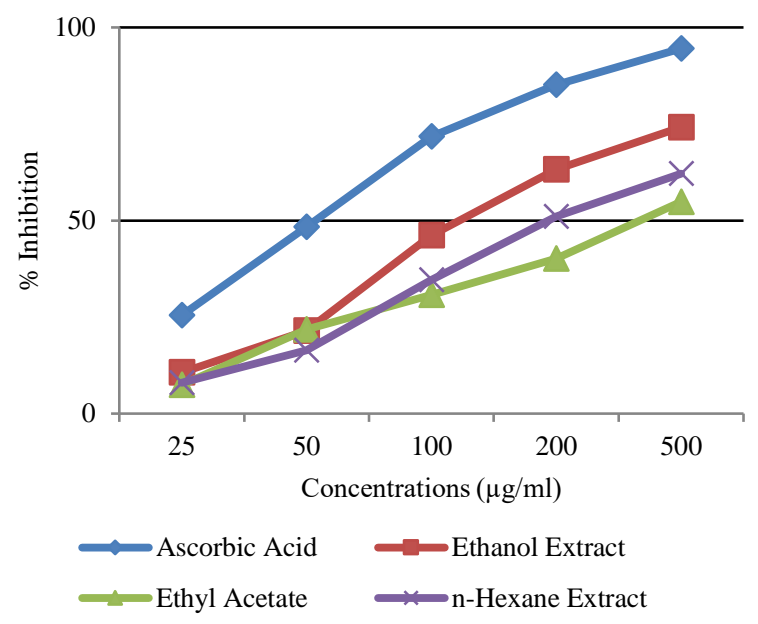

Fig. 10. Comparison of \% inhibition of ascorbic acid (standard) and various samples of Derris trifoliata.

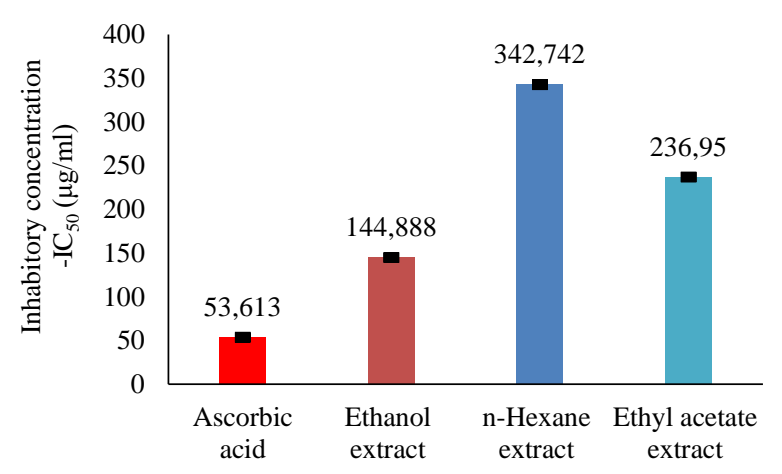

Fig. 11. $\mathrm{IC}_{50}$ values of standard (ascorbic acid) and different samples of Derris trifoliata. The results are represented as mean SEM (standard error of the mean).

\section{H. Nitric Oxide (NO) Scavenging Assay}

It is well known that nitric oxide has an important role in various inflammatory processes. Sustained levels of production of this radical are directly toxic to tissues and contribute to the vascular collapse associated with septic shock, whereas chronic expression of nitric oxide radical is associated with various carcinomas and inflammatory conditions including juvenile diabetes, multiple sclerosis, arthritis and ulcerative colitis [42]. The toxicity of NO increases greatly when it reacts with superoxide radical, forming the highly reactive peroxynitrite anion $\left(\mathrm{ONOO}^{-}\right)$ [43]. The nitric oxide generated from sodium nitroprusside reacts with oxygen to form nitrite. The extract inhibits nitrite formation by directly competing with oxygen in the reaction with nitric oxide. Derris trifoliata displayed free radical scavenging activity in the NO scavenging assay which is comparable to that of ascorbic acid a well-known standard antioxidant (Fig. 12). The activity was in the following order: Ascorbic acid> Ethanol extract $>$ Ethyl acetate extract $>n$ Hexane extract (Fig. 13).

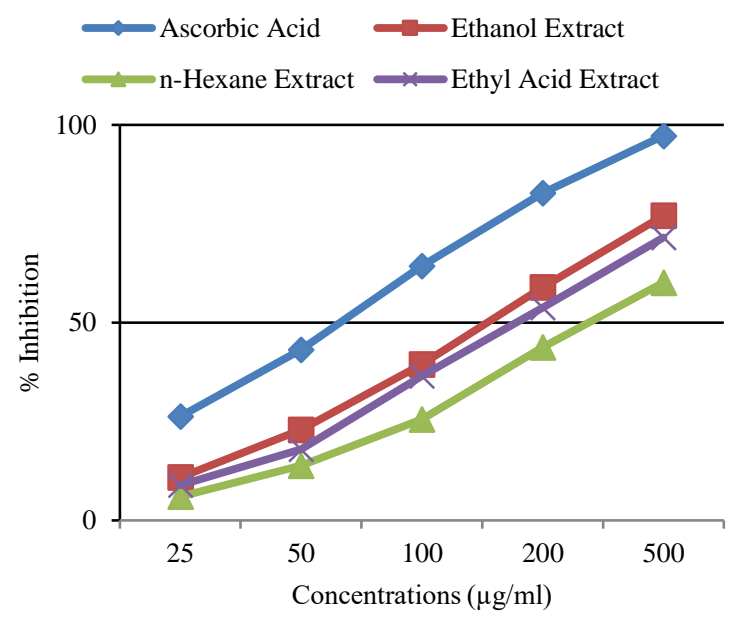

Fig. 12. Comparison of \% inhibition of ascorbic acid (standard) and various samples of Derris trifoliata.

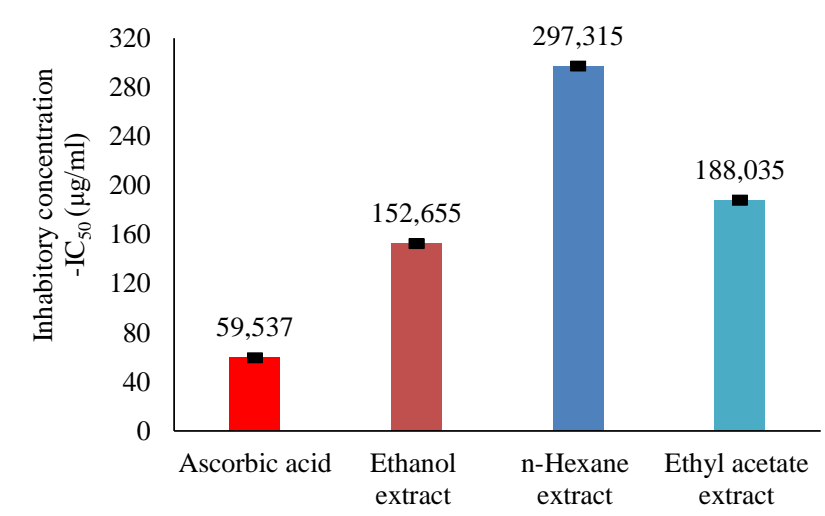

Fig. 13. $\mathrm{IC}_{50}$ values of standard (ascorbic acid) and different samples of Derris trifoliata. The results are represented as mean SEM (standard error of the mean).

\section{FRAP (Ferric reducing antioxidant power) assay}

FRAP assay measures the reducing potential of an antioxidant reacting with a ferric tripyridyltriazine $\left[\mathrm{Fe} 3^{+}-\right.$ TPTZ] complex and producing a coloured ferrous tripyridyltriazine [Fe2+-TPTZ] [44]. Generally, the reducing 
properties are associated with the presence of compounds which exert their action by breaking the free radical chain by donating a hydrogen atom. FRAP assay treats the antioxidants in the sample as a reductant in a redox-linked colorimetric reaction [45].

The reduction capacity of a compound may serve as a significant indicator of its potential antioxidant activity [46]. The FRAP assay treats the antioxidants contained in the samples as reductants in a redox-linked colorimetric reaction and the value reflects the reducing power of the antioxidants [47]. FRAP (Ferric Reducing Antioxidant Power) assay is presented as a novel method for assessing "antioxidant power." Frap assay measures the reducing potential of an antioxidant reacting with a ferric tripyridyltriazine $\left[\mathrm{Fe} 3^{+}-\right.$ TPTZ] complex and producing a colored ferrous tripyridyltriazine [Fe2+-TPTZ] [48]. Generally, the reducing properties are associated with the presence of compounds which exert their action by breaking the free radical chain by donating a hydrogen atom.

Derris trifoliata displayed free radical scavenging activity in the FRAP assay which is comparable to that of ascorbic acid a well-known standard antioxidant (Fig. 14). The activity was in the following order: Ascorbic acid> Ethanol extract $>$ Ethyl acetate extract $>$ n-Hexane extract (Fig. 15).

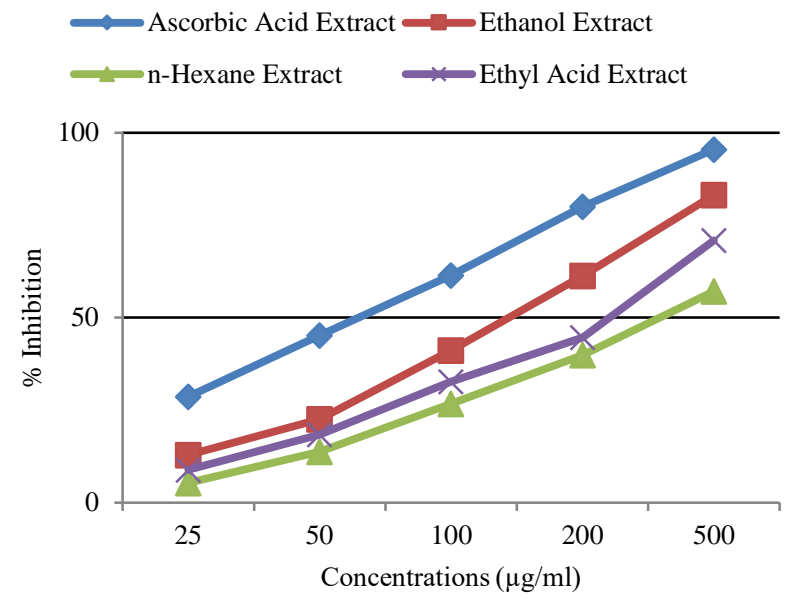

Fig. 14. Comparison of \% inhibition of ascorbic acid (standard) and various samples of Derris trifoliata.

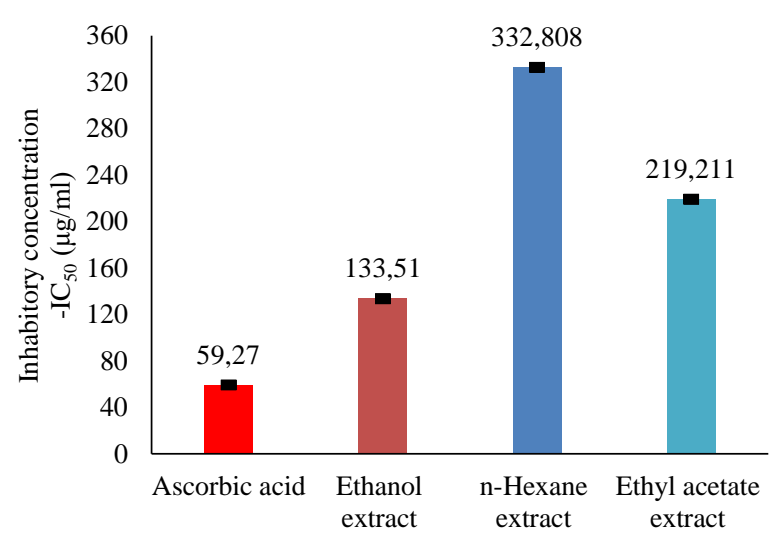

Fig. 15. $\mathrm{IC}_{50}$ values of standard (ascorbic acid) and different samples of Derris trifoliata. The results are represented as mean SEM (standard error of the mean)

\section{J. Ferrous Ion $(\mathrm{Fe}++)$ Chelating Ability Assay}

The iron-chelating capacity test measures the ability of antioxidants to compete with ferrozine in chelating ferrous ion. Ferrozine can quantitatively form complexes with $\mathrm{Fe}^{++}$. In the presence of sample possessing chelating activity, the formation of complexes is decreased. Therefore, measurement of the rate of color reduction helps to estimate the chelating activity of sample. Chelating capacity of the extract increased with increase in concentration. Ferrozine combines with ferrous ions forming a red colored complex which absorbs at $562 \mathrm{~nm}$. The addition of different plant extracts interferes with the ferrous ferrozine complex and the formation of the red colored complex decreased with the increasing concentration.

The two oxidation states of iron, $\mathrm{Fe}^{2+}$ and $\mathrm{Fe}^{3+}$ donate or accept electrons through redox reactions that are significant for biological reactions, but they also may be harmful to cells [49] In excess, iron helps superoxide anion $\left(\mathrm{O}^{\cdot 2-}\right)$ and hydrogen peroxide to convert into the extremely reactive hydroxyl radical $\left(\mathrm{OH}^{*}\right)$ (Haber-Weiss reaction) that cause severe injury to membranes, proteins and DNA [50]. It decomposes lipid hydro-peroxides into peroxyl and alkoxyl radicals responsible for the chain reaction of lipid peroxidation [51]. $\mathrm{IC}_{50}$ for $\mathrm{Fe}^{2+}$ chelating ability were 62.489 , $80.091,750$ and $130.32 \mu \mathrm{g} / \mathrm{ml}$ for ethyl acetate, ethanol and n-hexane extracts respectively (Fig. 17). However, compared to standard EDTA $\left(\mathrm{IC}_{50}=14.86 \mu \mathrm{g} / \mathrm{ml}\right)$., they show less activity.
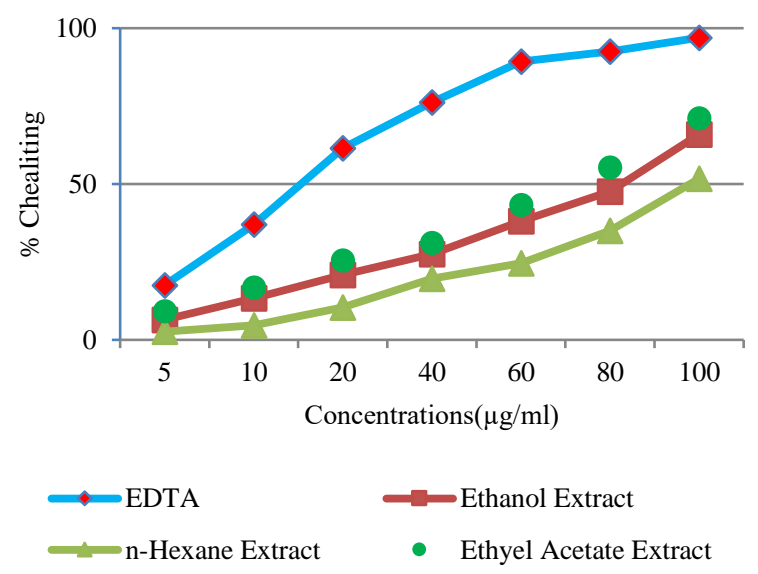

Fig. 16. Comparison of $\%$ chelation of EDTA (standard) and various samples of Derris trifoliata.

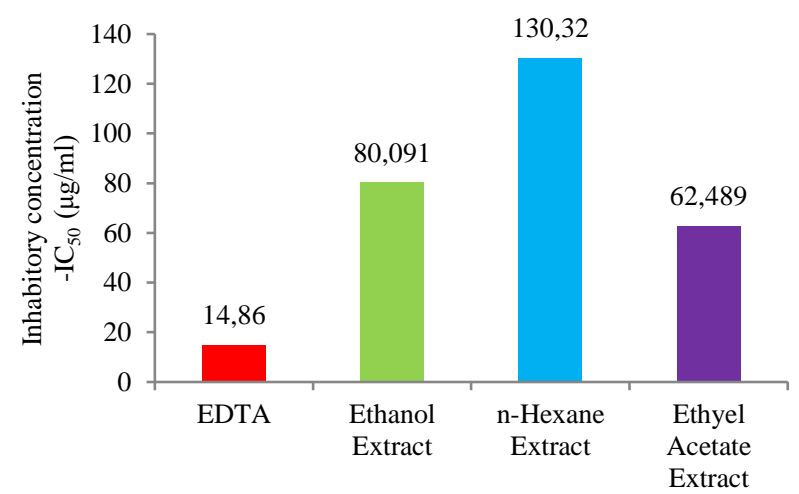

Fig. 17. $\mathrm{IC}_{50}$ values of standard (EDTA) and different samples of Derris trifoliata. The results are represented as mean SEM (standard error of the mean). 


\section{CONCLUSION}

In the present study, it is concluded that extracts of Derris trifoliata possess significant amount of antioxidant components. Further studies are required to fractionate the extract, to identify the bioactive compound(s) and should be directed to carry out in vivo studies of its medicinal active components in order to determine their exact mechanism of action and to improve nutritional profile and health benefits as well as to prepare natural pharmaceutical products of high value.

\section{ACKNOWLEDGMENT}

We give our gratitude to the authorities of Phytochemistry and Pharmacology Research Laboratory, Pharmacy Discipline, Life Science School, Khulna University, Bangladesh for providing financial and instrumental facilities. We would also like to express our profound gratitude and regards to our respectable supervisor Professor Dr. Md. Mustafizur Rahman (Pharmacy Discipline, Khulna University) for his guidance, suggestions, and advice throughout the course of study. Our thanks \& gratitude extend to Md. Ashiqul Islam (Lab Assistant, Pharmacy Discipline, Khulna University) for his kind and friendly cooperation.

\section{REFERENCES}

[1] Gani, Medicinal Plants of Bangladesh, $2^{\text {nd }}$ ed. Bangladesh: The Asiatic Society of Bangladesh; pp. 45-47, 2003.

[2] J. D. Witt, S. L. Warren, T. G. Ranney and J. R. Baker, "Biorational and Conventional Plant Protectants Reduce Feeding by Adult Japanese Beetles," J. Environ. Hortic, vol. 17, pp. 203-206, 1999.

[3] K.R. Kirtikar and B.D. Basu, "Indian Medicinal Plants," Dehradun, India: International Book Distributors; 1987.

[4] A. Bhattacharyya and C.R. Babu, "Purification and Biochemical Characterization of a Serine Proteinase Inhibitor from D. trifoliata Lour. Seeds: Insight into Structural and Antimalarial Features," Phytochemistry, vol. 70, no. 6, pp. 703-712, 2009.

[5] M.R. Khan, A.D. Omoloso and Y. Barewai, "Antimicrobial Activity of the D. Elliptica, D. Indica and D. Trifoliata Extractives," Fitoterapia, vol. 77, pp. 327-330, 2006.

[6] S. Tewtrakul, S. Cheenpracha and C. Karalai, "Nitric Oxide Inhibitory Principles from D. trifoliata Stems," Phytomedicine, vol. 16, pp. 568572, 2009.

[7] A. Yenesew, H. Twinomuhwezi, J.M. Kabaru, H.M Akala, B.T. Kiremire, M. Heydenreich, M.G. Peter, F.L. Eyase, N.C. Waters and D.D. Walsh, "Antiplasmodial and larvicidal flavonoids from Derris trifoliata." Bull Chem Soc Ethiop vol. 23, pp. 409-414, 2009.

[8] C.M.R. Gomes, O.R. Gottlieb, G.B.M. Bettolo, F. Dellemonache and R.M. Polhill, "Systematic Significance of Flavonoids in D. and Lonchocarpus," Biochemical Systematics and Ecology, vol. 9, pp. 129-147, 1981.

[9] G.E. Trease and W.C. Evans, "Pharmacognosy," $13^{\text {th }}$ ed. London: Bailliere Tindall; pp. 176-180, 1989.

[10] A. Prakash, "Antioxidant Activity, Analytical progress report of Medallion Laboratories," vol. 19, no. 2, pp. 1-2, 2001.

[11] G. Cioffi, M. D’Auria, A. Braca, J. Mendez, A. Castillo, I. Morelli, F. De Simone and N. De Tommasi, "Antioxidant and Free Radical ScavengingActivity of Constituents of the Leaves of Tachigaliapaniculata," Journal of Natural Products, vol. 65, pp. 1526$1529,2002$.

[12] K. Wolfe, X. Wu and R.H. Liu, "Antioxidant activity of apple peels," Journal of Agricultural and Food Chemistry, vol. 51, pp. 609-614, 2003.

[13] E.L.C. Amorim, J.E. Nascimento, J.M. Monteiro, S. Peixoto, T.A.S. Araujo and U.A.P. Albuquerque, "A simple and accurate procedure for the determination of tannin and flavonoid levels and some applications in ethnobotany and ethnopharmacology," Functional Ecosystem and Communities, vol. 2, pp. 88-9, 2008.
[14] S. Monic, R.B. Yerram and B. Jagadeesh, "Phytochemical screening and in- vitro antioxidant activity of aqueous and hydroalcoholic extract of Bacopa monnieri Linn," IJPSR, vol. 3, no. 9, pp. 3418-3424, 2012.

[15] M. Oyaizu, "Studies on product of browning reaction prepared from glucosamine," Japan Journal of Nutrition, vol. 44, pp. 307-315, 1986.

[16] G. Sudha, M.S Priya, R.I Shree and S. Vadivukkarasi, "In vitro free radical scavenging activity of raw pepino fruit (solanum muricatum aito)," International Journal of Current Pharmaceutical Research, vol. 3, no. 2, pp. 137-140, 2011.

[17] F.N. Seyed, M.N. Seyed, A.E. Mohammad and A. Hossein, "The antioxidant activity of wild medlar (Mespilusgermanica L.) fruit, stem bark and leaf," African Journal of Biotechnology, vol. 10, no. 2, pp. 283-289, 2011.

[18] R.J. Ruch, S.J. Cheng and J.E. Klaunig, "Prevention of cytotoxicity and inhibition of intracellular communication by antioxidant catechins isolated from Chinese green tea," Carcinogenesis, vol. 10, pp.1003, 1989.

[19] L.C. Green, D.A. Wagner, J. Glogowiski, P.L. Skipper, J.S. Wishnok and S.R. Tannenbaum, "Analysis of nitrate, nitrite, and $[15 \mathrm{~N}]$ nitrate in biological fluids," Analytica Biochem, 126: 131-138, 1982.

[20] A. Sharma, S. Bhardwaj, A. Mann, A. Jain and M. Kharya, "Screening Methods of Antioxidant Activity: An Overview," Pharmacognosy reviews, vol. 2, pp. 232-238, 2007.

[21] I.E.F. Benzie and J.J Strain, "The ferric reducing ability of plasma (FRAP) as a measure of antioxidant power: the FRAP assay," Analytica Biochem, vol. 239, no. 1, pp. 70-76, 1996.

[22] J.F. Haro-Vicente, C. Martinez-Gracia and G. Ros, "Optimization of in vitro measurement of available iron from different fortificants in citric fruit juices," Food Chemistry, vol. 98, no.1, pp. 639-648, 2006.

[23] P.D. Duh, Y.Y. Tu and G.C. Yen, "Antioxidant activity of water extract of Harug Jyur (Chrysanthemum morifolium Ramat)," Lebensmittel - Wissenchaft und Technologie, vol. 32, no.5, pp. 269$277,1999$.

[24] M.H. Gordon, "The mechanism of antioxidant action in vitro," In: BJF Hudson (Ed), Food antioxidants, Elsevier Applied Science, London. pp $1-18,1990$.

[25] J.R. Soares, T.C.P. Dins, A.P. Cunha and L.M. Ameida, "Antioxidant activity of some extracts of Thymus zygis," Free Radical Research, vol. 26, pp. 469-478, 1997.

[26] L.W. Chang, W.J. Yen, S.C. Huang and P.D. Duh, "Antioxidant activity of sesame coat," Food Chemistry, vol. 78, pp.347-354, 2002.

[27] P.D. Duh, Y.Y. Tu and G.C. Yen, "Antioxidant activity of water extract of Harug Jyur (Chrysanthemum morifolium Ramat)," Lebensmittel- Wissenchaft und Technologie, vol. 32, no.5, pp. 269277, 1999.

[28] I. Gülçin, M.T. Uguz, M. Oktay, S. Beydemir and Ö. I. Küfrevioglu, "Antioxidant and antimicrobial activities of Teucrium polium L." Journal of Food Technology, vol.1, pp. 9-17, 2003.

[29] T. Hatano, R. Edamatsu, M. Hiramatsu, A. Mori and Y. Fujita, "Effects of the interaction of tannins with co-existing substances. VI: effects of tannins and related polyphenols on superoxide anion radical and on 1,1-diphenyl-2-picrylhydrazyl radical," Chemical and Pharmaceutical Bulletin, vol. 37, pp. 2016-2021, 1989.

[30] N.P. Das and T.A. Pereira, "Effects of flavonoids on thermal autoxidation of palm oil: structure-activity relationship," Journal of the American oil chemists' society, vol. 67, pp. 255-258, 1990.

[31] N.S.C. De Gaulejac, Y. Glories and N. Vivas, "Free radical scavenging effect of anthocyanins in red wines," Food Resource International, vol. 32, pp. 327-333, 1999.

[32] N. Tamilselvi, P. Krishnamoorthy, R. Dhamotharan, P. Arumugam and E. Sagadev, "Analysis of total phenols, total tannins and screening of phytocomponents in Indigofera aspalathoides(Shivanar Vembu) Vahl EX DC," Journal of chemical and pharmaceutical research, vol. 4, no. 6, pp. 3259-3262, 2012.

[33] V. Koleckar, K. Kubikova, Z. Rehakova, K. Kuca, D. Jun, L. Jahodar and L. Opletal, "Condensed and hydrolysable tannins as antioxidants influencing the health," Mini Review in Medicinal Chemistry, vol. 8, pp. 436-447, 2008.

[34] V. Amico, R. Chillemi, S. Mangiafico and C. Spatafora, "Tringali, Polyphenol-enriched fractions from Sicilian grape pomace: HPLCDAD analysis and antioxidant activity," Bioresource Technology, vol. 99, pp. 5960-5966, 2008.

[35] Z. Maksimović, D. Malenčić and N. Kovačević, "Polyphenol contents and antioxidant activity of Maydis stigma extracts," Bioresource Technology, vol. 96, pp. 873-877, 2005.

[36] P. Ranju, G. Kundlik, S. Nidhi, M.H. Mohammed and N Thirumoorthy, "Antioxidant and free radical scavenging activity of ethanolic extract of Morinda citrifolia," Annals of Biological Research, vol. 2, no. 1, pp. 127-131, 2011. 
[37] V. Nagavani, Y. Madhavi, R.D. Bhaskar, R.P. Koteswara and R.T. Raghava, "Free radical scavenging activity and qualitative analysis of polyphenols by RP-HPLC in the flowers of Couroupita guianensis, Electronic Journal of Environmental," Agricultural and Food Chemistry, vol. 9, no. 9, pp. 1471-1484, 2010.

[38] K. Nagarajan, A. Mazumder and L.K. Ghosh, "In-vitro antioxidant activity of alcoholic extracts of Wrightia Tomentosa," Pharmacologyonline, vol. 1, pp. 196-203, 2008.

[39] R.L. Prior and G.H. Cao, "In-vivo total antioxidant capacity: comparison of different analytical methods," Free Radical Biology and Medicine, vol. 27, pp. 1173-1181, 1999.

[40] M.J. Jung, S.I. Heo and M.H. Wang, "Free radical scavenging and total phenolic contents from methanolic extracts of Ulmus davidiana," Food Chemistry, vol.108, pp. 482-487, 2008.

[41] M.J. Miller, H. Sadowska-Krowicka, S. Chotinaruemol, J.L. Kakkis and D.A. Clark, "Amelioration of chronic ileitis by nitric oxide synthase inhibition," Journal of pharmacology and experimental therapeutics, vol. 264, no. 1, pp. 11-16, 1993.

[42] B.S. Tylor, Y.M. Kion, Q.I. Wang, R.A. Sharpio, T.R. Billiar and D.A. Geller, "Nitric oxide down-regulates hepatocyte-inducible nitric oxide synthase gene expression," Archives of Surgery, vol. 132, pp. 1177$1183,1997$.

[43] H. Ischiropoulos, A.B. al-Mehdi and A.B. Fisher, "Reactive species in ischemic rat lung injury: Contribution of peroxynitrite," American Journal of Physiology, vol. 269, pp. 158-164, 1995.

[44] C. Guo, J. Yang, J. Wei, Y. Li, J. Xu and Y. Jiang, "Antioxidant activities of peel, pulp and seed fractions as determined by FRAP assay," Nutrition Research, vol. 23, pp. 1719-1726, 2003.

[45] B. Ercan, and K. Ekrem, "Evaluation of reducing power and radical scavenging activities of water and ethanol extracts from sumac (Rhus coriaria L.)," Food Research International, vol. 44, pp. 2217-2221, 2011.

[46] S. Meir, J. Kanner, B. Akiri and S. Philosoph-Hadas, "Determination and involvement of aqueous reducing compounds in oxidative defense systems of various senescing leaves," Journal of Agricultural and Food Chemistry, vol. 43, pp. 1813-1819, 1995.

[47] Y. Li, C. Guo, J. Yang, J. Wei, J. Xu and S. Cheng, "Evaluation of antioxidant properties of pomegranate peel extract in comparison with pomegranate pulp extract," Food Chemistry, vol. 96, pp. 254-260, 2006.

[48] I.E.F. Benzie and J.J Strain, "The ferric reducing ability of plasma (FRAP) as a measure of antioxidant power: the FRAP assay," Analytica Biochem, vol. 239, no. 1, pp. 70-76, 1996.

[49] Y. Yamaji, Y. Nakazato, N. Oshima, M. Hayashi and T. Saruta, "Oxidative stress induced by iron released from transferring in low $\mathrm{pH}$ peritoneal dialysis solution," Nephrology Dialysis Transplantation, vol. 19, no. 10, pp. 2592-2597,2004.

[50] E.R. Stadtman, "Protein oxidation and aging," Science, vol. 257, no. 5074, pp. 1220-1224, 1992.

[51] L.W. Chang, W.J. Yen, S.C. Huang and P.D. Duh, "Antioxidant activity of sesame coat," Food Chemistry, vol. 78, pp.347-354, 2002.

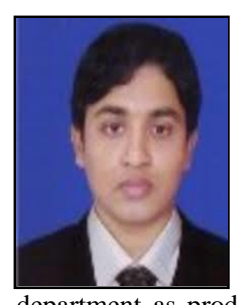

Arif Hossin is an industrial pharmacist. He born in Manirampur, Jashore, Bangladesh in 02 January 1989. He obtained his bachelor's and master's degrees in pharmacy from Khulna University, Bangladesh in 2012 and 2015 respectively.

He joined Square pharmaceuticals Limited, which is the number one pharmaceutical company in Bangladesh, in 15 June 2014 as quality assurance executive. In March 2016, he joined production department as production executive and since then he has been working there. He has seven (10) co-authored research papers published in different national and international journals. He has yearning for $\mathrm{MSc}$ and $\mathrm{PhD}$ degrees from abroad.

Mr. Hossin is a registered pharmacist under 'Pharmacy Council of Bangladesh' (PCB). He is a member of semanticscholar.org, researchgate.net and orcid.org. Mr. Hossin's research works can be found in semanticscholar.org profile.

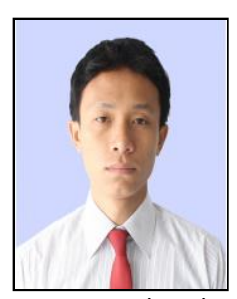

Beton Chakma is an industrial pharmacist. He born in Khagrachari Sadar, Khagrachari, Bangladesh in 01 April 1988. He received his bachelor's degree in pharmacy from Khulna University, Bangladesh in 2011.

He worked for Healthcare pharmaceuticals Ltd. and Orion Pharmaceuticals Ltd. before moving for Square pharmaceuticals Ltd. in 29 may 2017 as production executive. He wishes to obtain higher degrees from
Mr. Chakma is a registered pharmacist under 'Pharmacy Council of Bangladesh' (PCB).

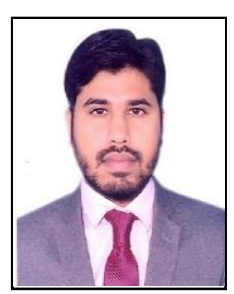

Md. Ali Imam Raju born in Kalaroa, Satkhira, Bangladesh on November 27, 1988. He earned his bachelor's and master's degrees in pharmacy from Khulna University, Bangladesh in 2012 and 2015 respectively.

$\mathrm{He}$ worked for Radiant pharmaceuticals Ltd. and Renata Pharmaceuticals Ltd. before joining Square pharmaceuticals Ltd. in 05 January 2015 as quality assurance executive. He wants to achieve higher degrees from overseas university.

Mr. Raju is a registered pharmacist under 'Pharmacy Council of Bangladesh' (PCB). 